\title{
Corrigendum: The gendered construction of reparations: an exploration of women's exclusion from the Niger Delta reintegration processes
}

\section{Olakunle Michael Folami}

Correction to: Palgrave Communications (2016) 2 Article number: 16083 doi: 10.1057/palcomms.2016.83; Published 6 December 2016; Updated 20 December 2016

"Niger Delta" was previously not capitalised in the title as it should have been. This has been corrected.

The article has been corrected online. 